\title{
Pulmonary hypertension complicating portal vein thrombosis
}

\author{
J B SAUNDERS, T J CONSTABLE, DONALD HEATH, PAUL SMITH, AND A PATON
}

\begin{abstract}
From the Department of Medicine, Dudley Road Hospital, Birmingham, and the Department of Pathology, University of Liverpool, Liverpool, UK
\end{abstract}

The syndrome of portapulmonary hypertension is well recognised but the cause of the association is obscure. We describe the history of a 24-year-old man who developed this syndrome, and in whom the findings at necropsy included the hitherto unreported association of adenomatous hyperplasia of the liver.

\section{Case report}

A 24-year-old Indian man died in 1977 after a long illness that began in 1961 (aged 8 years) with a severe gastrointestinal haemorrhage. Laparotomy showed large oesophageal varices that were oversewn. The spleen was enlarged but the liver looked normal. After a further gastrointestinal bleed in 1966 he underwent splenic venography, which showed a small, poorly opacifying portal vein and extensive oesophageal varices. Splenectomy and lienorenal anastomosis were performed. Chest radiography was normal.

He remained well until 1972 when he developed pneumonia. Cardiac catheterisation at this time showed a mean pulmonary arterial pressure of $64 \mathrm{mmHg}$, a mean wedge pressure of $5 \mathrm{mmHg}$, and a pulmonary vascular resistance of 826 dyne $\mathrm{s} \mathrm{cm}^{-5}$. Pulmonary angiography showed aneurysmal dilatation of the pulmonary trunk and pruning of the peripheral vessels but no sign of thromboembolism. Hepatic wedge pressure was $3 \mathrm{mmHg}$. Results of spirometry, liver function tests, and a liver biopsy were normal. He was treated with anticoagulants but his exercise tolerance gradually decreased, and in 1976 he developed signs of right heart failure from which he died in July 1977.

\section{PATHOLOGICAL FINDINGS}

Post-mortem examination showed gross right ventricular and right atrial hypertrophy. Total heart weight was $502 \mathrm{~g}$, right ventricle $290 \mathrm{~g}$, left ventricle and septum $121 \mathrm{~g}$ (ratio $\mathrm{L}: \mathrm{R} 0.41$ ), atria $91 \mathrm{~g}$. The cardiac valves were structurally normal, and there were no septal defects. Histological examination of the right ventricular myocardium showed hypertrophy of the muscle fibres with boxlike nuclei. The pulmonary trunk was greatly dilated and showed extensive areas of cystic medial degeneration in which there were small tears, indicative of early dissection. Histologically, the media had a "moth-eaten" appearance with numerous areas where the elastic lamina had been lost, being replaced by acid mucopolysaccharide. There was severe intimal fibrosis.

The elastic pulmonary arteries were thick and atheromatous. The muscular pulmonary arteries (those between 100 and $1000 \mu \mathrm{m}$ in diameter) were dilated and many were occluded by intimal fibroelastosis of "onion-skin" type. Their media appeared thinned, distended, and infiltrated by intimal fibroelastic tissue. Many branches were extremely thin and dilated, and clustered around parent vessels (fig 1) or in the lung parenchyma. Some branches contained plexiform arrangements of cells which appeared to have arisen either from the intima or in continuity with cellular components of the media. Such appearances constitute

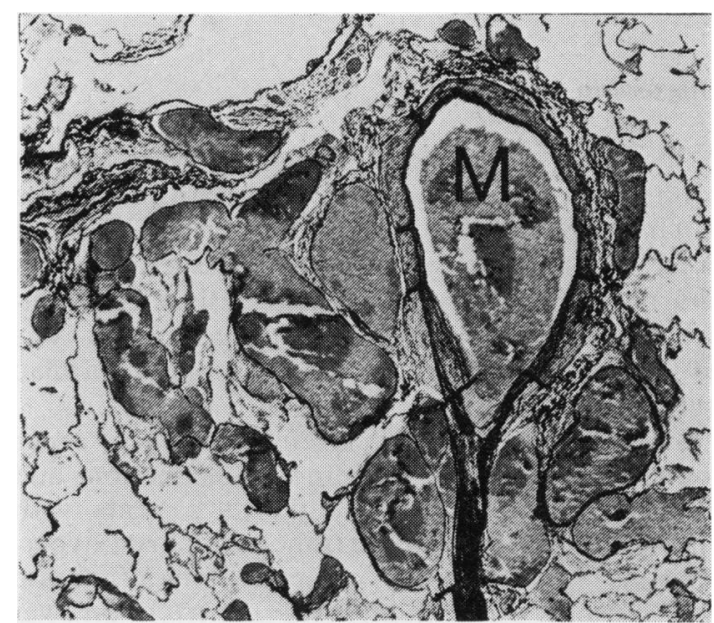

Fig 1 Oblique section of muscular pulmonary artery (M) with occluded arteriolar branch running downwards, surrounded by clusters of thin-walled vessels (Elastic van Gieson $\times 144)$. 
"plexiform lesions" of some maturity, indicative of long-standing severe pulmonary hypertension. There was no evidence of pulmonary thromboembolism, veno-occlusive disease, or portapulmonary venous anastomoses.

The liver was small (956 g) and on section showed a pronounced nutmeg pattern of centrilobular venous congestion with multiple, sharplydefined white areas of adenomatous hyperplasia (fig 2). There was no evidence of cirrhosis. A patent portal vein could not be found; sections through the porta hepatis showed cavernomatous transformation. The site of the lienorenal shunt was found to be occluded, and numerous varices were present.

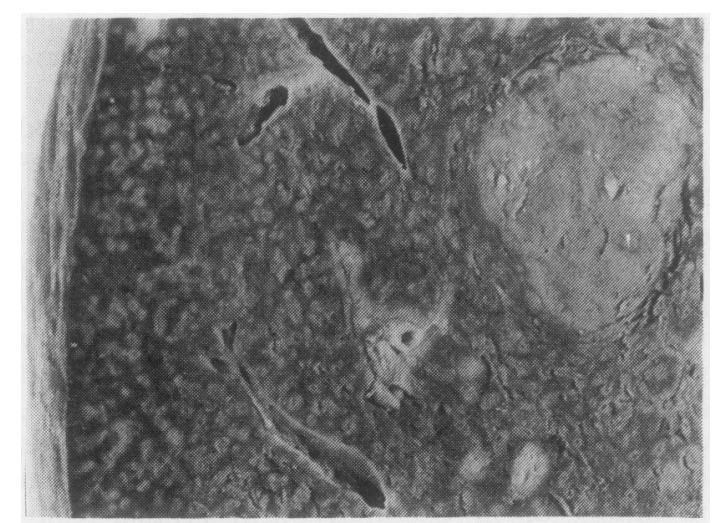

Fig 2 Liver showing pronounced "nutmeg pattern" of severe venous congestion. Nodule of adenomatous hyperplasia to right $(\times 3.5)$.

\section{Discussion}

A moderate degree of pulmonary hypertension is common in patients with portal hypertension due to cirrhosis, but those patients described by Segel et al (1963) had raised pulmonary wedge pressures and normal pulmonary vascular resistances, indicating that their pulmonary hypertension was passive, probably secondary to a high cardiac output.

Severe pulmonary hypertension of the order found in our patient is distinctly uncommon, and although found predominantly in patients with cirrhosis may be seen in extrahepatic portal hypertension (Naeye, 1960). In our patient liver function was normal when pulmonary hypertension was diagnosed, and deteriorated only when he developed progressive right heart failure.

Pathologically the type of pulmonary vascular disease that occurs in association with portal hypertension is characterised by plexiform lesions of the muscular pulmonary arteries and, in some cases, necrotising arteritis ("plexogenic pulmonary arteriopathy"). The mechanism by which these changes arise is obscure. This form of vascular disease is also seen in patients with "primary" के pulmonary hypertension and in some with congenital cardiac shunts. Intrapulmonary arteriovenous anastomoses and portapulmonary venous anastomoses occur in patients with liver disease (Harris and Heath, 1977), and hypertension may possibly develop as a result of increased blood flow via these channels. No such anastomoses were, however, found in our patient.

Naeye (1960) found emboli in the small pulmonary arteries in five of his cases and regarded 옹 these as the cause of the pulmonary hypertension. We believe they were superimposed on pre- $\frac{7}{0}$ existing vascular damage since the histological features of plexogenic pulmonary arteriopathy are $\vec{\theta}$ quite distinct from those of recurrent pulmonary thromboembolism (Harris and Heath, 1977). Our patient showed no evidence of thromboembolism.

A humoral mechanism for the development of pulmonary hypertension is an attractive alternative. It is well established that some substancesfor instance fulvine-affect both the liver and the pulmonary vasculature. When fulvine is administered to rats those that survive acute hepatic necrosis develop hypertensive pulmonary vascular disease (Kay et al, 1971), probably as a result of passage to the pulmonary circulation of a metabolite of fulvine. In cirrhosis and portal hypertension dietary metabolites or vasoactive compounds normally removed by the liver may possibly find their way to the lungs. The nodules of adenomatous hyperplasia found in our patient may also not be as innocent as is generally thought (Klemperer, 1928). Whether such nodules could secrete a vasoactive substance that causes pul- $\frac{7}{0}$ monary vasoconstriction and whether a similar mechanism could occur in certain patients with $\mathcal{N}$ cirrhosis are possibilities that might be worth $N$ exploring in the future.

Electron microscopic appearances of the pul- $\frac{\omega}{O}$ monary lesions will be discribed in a subsequent paper.

\section{References}

Harris, P, and Heath, D (1977). The Human Pulmonary Circulation, 2nd edn. Churchill Livingstone, $\frac{\rho}{\Phi}$ Edinburgh.

Kay, J M, Heath, D, Smith, P, Bras, G, and Summerell, J (1971). Fulvine and the pulmonary 8 circulation. Thorax, 26, 249-261.

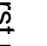


Klemperer, $P$ (1928). Cavernomatous transformation of the portal vein. Its relation to Banti's disease. Archives of Pathology, 6, 353-377.

Naeye, R L (1960). "Primary" pulmonary hypertension with coexisting portal hypertension. A retrospective study of six cases. Circulation, 22, 376-384.

Segel, N, Bayley, T J, Paton, A, Dykes, P W, and
Bishop, J M (1963). The effects of synthetic vasopressin and angiotensin on the circulation in cirrhosis of the liver. Clinical Science, 25, 43-55.

Requests for reprints to: Dr J B Saunders, Department of Medicine, Dudley Road Hospital, Birmingham B18 7QH. 